\title{
A beer a minute in Texas football: Heavy drinking and the heroizing of the antihero in Friday Night Lights
}

International Review for the Sociology of Sport 20I4, Vol. 49(3/4) 45I-467 (c) The Author(s) 2013 Reprints and permissions: sagepub.co.uk/journalsPermissions.nav DOI: $10.1177 / 1012690213495535$

irs.sagepub.com

\section{Robert L Kerr}

University of Oklahoma, USA

\begin{abstract}
This article applies a qualitative framing analysis to the first three seasons of the television series Friday Night Lights, focusing particularly on its incorporation of heavy drinking into narrative representations of the player whose character is most consistently central to the game of football as fictionally mediated in small-town Texas over the course of those three seasons. The analysis suggests that over the course of that period Friday Night Lights embeds nuanced social meanings in its framing of alcohol use by that player and other characters so as to associate it with multiple potential outcomes. Yet among those outcomes, the most dominant framing works to, in effect, reverse a progression through which media representations historically evolved from a heroic model toward an antihero model, with heavy drinking central to that narrative process of meaning-making in such messages.
\end{abstract}

\section{Keywords}

cultural analysis, football, Friday Night Lights, masculinity, meaning making, mediated sport, social construction, sports media, television, Texas football

The manner in which meaning has been socially constructed and contested through mediated representations of the game of American football has proven a useful focal point for cultural analysis. The story of football has been characterized as "inextricably tied to ... the media, each developing very differently if not for each other" (Oriard, 2001: 11). Indeed, since the beginnings of the game's development in the late 19th century, it has been experienced to a far greater degree through mediated texts, such as news and promotional accounts and literature, than through firsthand experiences with the game itself. The phenomenon can be considered as an example of what Eric Hobsbawm called an "invented tradition" through which "promoters created rituals ... for the young

\section{Corresponding author:}

Robert L Kerr, University of Oklahoma, 395 W Lindsey, Norman, OK 73019-420I, USA.

Email: rkerr@ou.edu 
nation in quest of its identity and character" (Hobsbawm, 1983: 1). Through that process, media played an integral role in connecting the game to "a large number of American fans whose values are such that they coincide with the forms and conditions of football" (Falk, 2005: 242). Given that "the beer, sport, and men nexus has a long cultural history" (Wenner and Jackson, 2009: 6), consumption of alcohol often is integrally framed in such mediated representations.

This article applies qualitative framing analysis to the first three seasons of the television series Friday Night Lights, focusing particularly on its incorporation of heavy drinking into narrative representations of the player whose character is most consistently central to the game of football as fictionally mediated in small-town Texas over the course of those three seasons. The analysis suggests that over the course of that period Friday Night Lights embeds nuanced social meanings in its framing of alcohol use by that player and other characters so as to associate it with multiple potential outcomes. Yet among those outcomes, the most dominant framing works to, in effect, reverse a progression through which media representations historically evolved from a heroic model toward an antihero model, with heavy drinking central to that narrative process of meaning-making in such messages. That sense of both extending historically resonant representations while also redirecting them suggests a multifaceted variation on the sort of "continuity with the past" advanced through Hobsbawm's concept of "invented tradition" through which "a set of practices, normally governed by overtly or tacitly accepted rules and of a ritual or symbolic nature ... seek to inculcate certain values and norms of behaviour by repetition" (Hobsbawm, 1983: 1).

\section{The Merriwell and Billy Clyde models of the American football player}

Created on college campuses in the Northeast region of the United States in the late 19th century, American football gained quickly in popularity among other colleges and then high schools, and by the mid 20th century had begun to rival baseball nationally in popularity (Oriard, 2001: 6). Any number of accounts in the early years of football's development represented the game in terms of glowing idealizations. Walter Camp, a 19th-century Yale star who introduced coaching to the game and was its most successful early promoter, published 20 books and countless newspaper and magazine articles, with emphasis on the "purity" of the college football star who "plays as a gentleman . . . Whatever bruises he may have in the flesh, his heart is right" (Camp, 1984: 165-167). Such rhetoric would help establish a tradition in which football's spokespersons sought to imbue football with qualities more socially palatable (and marketable) than the essentially brutal struggle at its core. Such "appeals to sportsmanship implied the importance of tradition, timeless values of right and wrong, a stable social order - the world as imagined or desired by the privileged classes" (Oriard, 1991: 16).

The association between football and masculinity was actively cultivated. In the late 19 th and early 20 th centuries, when the United States faced no major military engagements, football was seen as "an alternative training ground for restoring masculinity and aggressiveness" (Gems, 2000: 96-99). The game came to be seen on many levels as a sport that segregated "boys from girls, men from women" (Falk, 2005: 11). 
Its male socialization patterns contributed to "beliefs and behaviors that reinforced patriarchy and dominance rationalized as mental, physical, and moral development" (Gems, 2000: 63).

Yet the violence of the game frequently generated intense criticism and pressure, leading at times to demands for its abolition (Moore, 1984: 187). Particularly high levels of brutality and other abuses during the 1905 season came very close to producing a ban on the game (Smith, 1981: 5). For decades, however, well into the mid 20th century, that side of the game remained remote from media representations that were widely grounded in what Oriard has called the "Frank Merriwell model of gee-whiz modesty" (1993: 280). In some 850 magazine installments and 217 novels (written by Gilbert Patten, under the pseudonym "Burt L Standish"), fictional Yale football star Frank Merriwell became one of the most famous heroic figures in all American fiction through a series of adventures and "athletic triumph after athletic triumph - all in an atmosphere of joviality, boyish enthusiasm, and sterling virtue" (Oriard, 1982: 28). The heroic "Merriwell model" typified most media representations of players until the latter decades of the 20th century, and was widely maintained by coaches in their media statements as well. "If the fans would pattern their sportsmanship after that of the players themselves," Bud Wilkinson, one of college football's most successful coaches of the mid 20th century, wrote, "the game would come much nearer to fulfilling the purpose for which it was created, a clean robust autumnal sport for college men" (Wilkinson, 1955).

Within a few years of that statement, however, coaches would increasingly begin finding such notions confronted by a "tidal wave of irreverent, outspoken athleteindividuals" (Clark, 1993: 110). Their arrival on the scene foreshadowed "the abandonment of the Frank Merriwell model . . . for the pervasive finger-pointing, fist-pumping, elaborately choreographed antics" that soon would come to dominate American sport (Oriard, 1993: 280). During a period when the rise of anti-establishment figures such as Elvis Presley, James Dean, and Marlon Brando was increasingly reflected in the popular culture of television, music, and film, media representations of such behavior by football players would soon become more common as well, signaling the cultural and commercial appeal of the antihero athlete.

As the cultural revolution of the 60 s unfolded and youth culture rose in influence, the Merriwell model gave way to more marketable imagery associating celebrity athletes with rebellion (Oriard, 2007: 52). In fictional representations, a new archetype arose in Billy Clyde Puckett of Dan Jenkins' 1972 novel Semi-Tough. Oriard called the "outlandishly raunchy humor" of the comic novel "the most complete portrait of the stud football player in American fiction" (1982: 190). Frank Merriwell wooed his longtime sweetheart with two kisses over a period of many years before marrying her, but "Billy Clyde and his teammates live out the male fantasy of abundant and perfect sex" (Oriard, 1982: 191). Whereas the Merriwell model idealized the football player as traditionally heroic, even noble, the historical progression of mediated representations toward the Billy Clyde Puckett model championed the antihero's self-centered womanizing and hard partying over sterling, "gee-whiz" virtue. This overview, though not exhaustive, highlights undeniably prominent trends over the course of media representations in American football's history of roughly a century and a half, emphasizing dramatic evolution in portrayals of 
"the public image of the football hero" (Oriard, 2007: 52). While not denying other representations of the heroic and antiheroic in sport, this study considers Friday Night Lights through the lens of the well established and widely utilized Merriwell and Puckett models.

This study's consideration of those models contributes to bodies of research on masculinity and media representations of alcohol use. Scholarly interest in the former has placed masculinity "under the microscope as never before" (Beynon, 2002: 3), particularly since the early 1990 s when research suggested that the investigation of popular media like "sports programmes, war movies, Playboy and Penthouse" could be significant in understanding constructions of masculinity (Van Zoonen, 1991: 48-49). In an age when "television sport, the tabloid press and celebrity culture" pervade daily life like never before, sports figures have become "the site of intersecting discourses of morality and masculinity" (Whannel, 2007: 9). Work on the subject has argued that "the masculine position" has come to be seen as being "as culturally located as that of femininity, and with it, all those aspects of sport not previously considered as gendered, because they were not associated with women, have revealed themselves to be subliminally marked as masculine." (Kennedy, 2007: 22). Research has asserted convincingly, however, that there is "no single essential trans-historical and trans-cultural masculinity (Whannel, 2007: 7), with studies focused on historical periods spanning many centuries (Brailsford, 1969; Cohen, 1996; Crowther, 1996; Dawson, 1994; Mangan, 1981; Roper and Tosh, 1991; Wiedemann, 1992) demonstrating that masculinity is "always shaped in ways that have a social and historical specificity" (Whannel, 2007: 7), and indeed, even in any given historical period there are competing masculinities (Connell, 1995). Therefore, masculinity must be seen as "far from being a stable entity" and one that can be manifest in multiple ways (Kennedy, 2007: 23).

Considering Friday Night Lights in terms of the models discussed above thus contributes analysis of its use of competing masculinities as well as its representations in which multiple outcomes are associated with alcohol use. Many studies have found media representations of alcohol to be not only frequent (DuRant et al., 1997; Mathios et al., 1998; Wallack et al., 1990) but quite often something "presented in a non troublesome context and as an integral part of normative behavior" (Cafiso et al., 1982: 1241). In that process, alcohol use tends to be represented as an unproblematic or neutral activity (Breed and DeFoe, 1979; Gerbener et al., 1981, 1986; Wallack, 1980) and quite often one that is disproportionately associated with glamour and success to the extent that even relatively moderate media consumption may well result in substantial exposure to inordinately glamorized depictions of alcohol use (DuRant et al., 1997: 1131). As this study's analysis shows, dominant representations in Friday Night Lights stand as markedly nuanced in regard to manifestations of masculinity and associations of multiple outcomes with alcohol use and the interrelationships between the two. As Kennedy articulated it, scholars today are called "not simply to analyse the texts of media sport, but also to think about the positions from which these texts can be read," to closely "look not only at the images of sport in the media, but also at the ways these images ask to be looked at" (24). By doing so, we consider "the ways in which masculinities are subject positions constructed in relation to the media representations" and the manner through which "different forms of sport media can therefore reveal the plurality of masculinities constructed in sport and 
allow us to consider how these masculinities are presented for consumption" (Kennedy, 2007: 24-25).

\section{Friday Night Lights}

Friday Night Lights stands as one of the most successful mediated representations of American football of recent years, generating popular texts first in print and later in cinema and then television. Reaching television audiences has brought the story by far the most attention, and in that regard is worthy of this study's scholarly examination because the network series represents a significant manifestation of two of the most powerful dynamics driving cultural understanding of the game of American football today. First of all, Friday Night Lights' development for the medium of television brought it into the venue that in the 20th and 21 st centuries has not only provided the most dominant showcase for the sport to date, but has "dramatically multiplied the number of people who care about it [and] significantly enlarged the role it plays in their lives" (Dunnavant, 2004: xvi). But even more crucial to the remarkable prominence Friday Night Lights has achieved with television audiences is the fact that its highly successful translation for a broad primetime audience vaulted it beyond the relatively limited consciousness of actual sports fans and into a second life as a much broader popular-entertainment brand. That makes all the difference in a world in which American football increasingly confronts the postmodern reality that it is "a product in the entertainment business, competing against not just baseball and basketball but also MTV, blockbuster movies, video games, and everything else vying for Americans' leisure time and loose dollars" (Oriard, 2007: 3). The television series began in 2006, two years after a major Hollywood movie was developed from the 1990 New York Times bestselling nonfiction book by HG Bissinger - all with the same title. The book, which told the story of one season of the Odessa Permian (Texas) High School football team, received much critical acclaim and was still selling 40,000 copies a year nearly two decades after its publication (Bissinger, 2004: 50). In a 2002 list of the 100 greatest sports books - based on a standard of "sportswriting [that] transcends bats and balls to display all the traits of great literature: incision, wit, force and vision, suffused with style and substance" - Sports Illustrated ranked Bissinger's book fourth. The magazine described it as "a brilliant look at how Fridaynight lights can lead a town into darkness" (McEntegart et al., 2002: 128).

But it is as a television series that Friday Night Lights has received by far the most phenomenal critical and audience attention. The New York Times described the television series as "the most visually sensual series perhaps ever seen on television" and "a melodrama in the most redemptive sense of the term, elevating our understanding of the form the way .. . Balzac and James did" (Bellafante, 2007: B17). Outside magazine told its readers, "There is no better show right now on the planet. Not inside, at least" (Sides, 2007: 97). The show ranked second, after the long-running cable-television dramaticseries hit The Sopranos, in a 2006 Broadcasting \& Cable magazine critics' ranking of the best shows on television (Grossman, 2007: 3). Friday Night Lights consistently ranked at or near the top of such rankings all the way to the end of its run in 2011, when Time ranked its finale the top television episode of the year (Poniewozik, 2011) and the series was honored with Emmy awards for writing and acting. Such critical acclaim embraced 
Executive Producer Peter Berg's expressed vision to "explore not only high school culture and sports culture but American culture in general" (Malone, 2006: 22). The New York Times declared his vision of "football and America and high school" to be "not just television great but great in the way of a poem or a painting, great in the way of art with a single obsessive creator who doesn't have to consult with a committee" (Heffernan, 2006: E1). While Friday Night Lights' audience totals did not place it at the top of the ratings, its devoted viewer base proved vigorous in its lobbying of network executives on behalf of the show, including one effort that resulted in fans mailing the network some 20,000 footballs as a show of support for the program's renewal. Critical acclaim and that sort of audience intensity kept the series on the air for five seasons (Garner, 2008: 8).

This analysis focuses on socially constructed meaning in that exploration of American culture as manifest through Texas high school football. The analysis reveals the manner in which that construction offers powerful consonance with the social milieu in which it is shaped, while utilizing competing masculinities in the process of developing representations in which a range of multiple outcomes are associated with alcohol use. The focus is on the first three seasons of Friday Nights Lights, a period over which the show completed most story arcs of the main characters introduced in the series' first season. Qualitative framing analysis is utilized to interrogate the text and its incorporation of heavy drinking into narrative representations of the player who, among those original characters, is most consistently central to the game of football in Friday Night Lights' small-town Texas milieu.

\section{Methodological and theoretical context}

Media representations of the game of football offer "powerful cultural text[s]" that "tell stories that serve individual needs from wherever they arise" (Oriard, 1993: 276-282). Carey proposed that analysis of such narratives can reflect efforts to utilize cultural ideals of an era to create "systems of meaning, and standards of reality shared by writer and audience" (1974: 5). Asserting that "the essence of sport is to be found within the nature of its relationship to the broader stream of societal forces of which it is a part," Sage has urged researchers to "approach sport relationally, always asking, 'What are the interconnections of sport to other aspects of American society?"' (Sage, 1998: 14). Similarly, Polumbaum and Wieting have contended that "mining sports stories for nuance, background, contradiction, and complication is a productive way to study the prevalent 'moral order' of a given community" (1999: 70-71).

To that end, framing analysis was utilized as a means of structuring this qualitative study focused upon relationships among sport, alcohol, and masculinity. The concept of framing can be particularly useful in studies of the ways that media producers construct representations of reality. Gamson conceptualized the media frame as "a central organizing idea used for making sense of relevant events," which can provide a basis for exploring how readers may "understand and remember a problem" (1989: 157). Gitlin defined media frames as "persistent patterns of cognition, interpretation, and presentation, of selection, emphasis, and exclusion" (1980: 7). In this study of social meanings embedded in sport-related drinking in Friday Night Lights, framing analysis provided a methodological discipline for guiding the critical evaluation of the television series' 
representations of drinking and drinkers. Those representations were evaluated in terms of the way they utilized narrative elements in a manner that contributed to recurring themes and dominant frames. Such analysis seeks to identify "the specific properties of the ... narrative that encourage those perceiving and thinking about events to develop particular understandings of them . . . and [that] convey thematically consonant meanings across media and time." This approach to analysis does not eliminate all inconsistent or incongruent information from texts, but on balance serves to "render one basic interpretation more readily discernible, comprehensible, and memorable than others" (Entman, 1991: 7).

Specifically, this form of framing analysis employed Altheide's "document analysis" process to connect the media representations that are the focus of the study to broader ideas in discourse and ideology (1996: 23-44). Altheide's approach defines the conceptual relationship of discourse, themes, and frames in this manner: "The actual words and direct messages of documents carry the discourse that reflects certain themes, which in turn are held together and given meaning by a broad frame. . . Frames are a kind of 'super theme"" (1996: 31). This method relies less on counting than on qualitative identification of prominent themes through a multi-step process (Altheide, 1996: 31). This process involves developing context for the sources of documents to be analyzed, examining a small number of the documents to begin developing categories to guide data collection, testing the categories on more documents, revising the categories, implementing "progressive theoretical sampling" (which refers to "the selection of materials based on emerging understanding of the topic under investigation"), collecting data, performing data analysis (which "consists of extensive reading, sorting, and searching through" the documents), comparing and contrasting extremes and key differences, summarizing findings, and integrating findings with interpretation (Altheide, 1996: 31).

This methodological approach is not without bias, but it does provide a systematic framework to guide the critical evaluation of relevant texts. As Gamson and Modigliani have discussed, "Media discourse is part of the process by which individuals construct meaning" (1989: 2). Considering framing in this context suggests that texts potentially represent symbolic meaning relevant to both communicators and receivers, both of which influence and are influenced by the times and culture in which they live. Therefore, the analysis in this research focuses most directly on the texts involved, embracing Entman's assertion that "whatever its specific use, the concept of framing consistently offers a way to describe the power of a communicating text" (Entman, 1993: 52-53). While it cannot ultimately tell us definitively how audiences understand media representations such as Friday Night Lights, it offers insight into the making of meaning through prominent ideas disseminated in the media universe in which audiences live.

In this study's framing analysis, the dominant frame that emerged over the first three seasons of Friday Night Lights was a constructed relationship between masculinity and alcohol that can be contextualized as constructive, destructive, or neutral and which can advance an antiheroic or heroic model of embedded meaning in representations of football players. That dominant frame appears in Friday Night Lights through consistent and qualitative emphasis on what will be discussed here in terms of five themes: 
- Representations of the character Tim Riggins and others in the context of drinking as part of constructive outcomes;

- representations of the character Tim Riggins and others in the context of drinking as part of destructive outcomes;

- representations of the character Tim Riggins and others in the context of drinking as part of neutral outcomes;

- representations of the character Tim Riggins in the context of drinking as part of advancing the Billy Clyde (antihero) model; and

- representations of the character Tim Riggins in the context of drinking as part of advancing the Merriwell (heroic) model.

As detailed further above, those themes were identified by using Altheide's process of qualitative content analysis in which the "actual words and direct messages of documents" are considered to provide "discourse that reflects certain themes." Those themes are then "in turn ... held together and given meaning by a broad frame that represents "a kind of "super theme"'or dominant frame (Altheide, 1996: 31). In the sections that follow, the actual words and messages most prominent in the construction of the first three seasons of Friday Night Lights are focused upon so as to highlight the themes noted just above and the manner in which they are given meaning in the context of the dominant frame. It offers insights into one of the most successful popular sports-media texts of recent years, illuminating many of "the ways in which masculinities are subject positions constructed in relation to the media representations" and further revealing "the plurality of masculinities constructed in sport and ... how these masculinities are presented for consumption" (Kennedy, 2007: 24-25).

\section{The making of meaning in the story of Friday Night Lights' hardest drinking player}

In terms of the players on the field in its fictional story, Friday Night Lights debuted with its focus on a classic Merriwell-model figure in the fictional Texas town of Dillon. Jason Street, considered to be the best high school quarterback in the state, is clean-cut, modest, and devoted to family, church, and community (Pilot, 2007). But after an injury in the first episode renders him a quadriplegic, his playing days end and narratively the focus on him shifts to his long struggle to build a new life off the field.

So it is Street's best friend, fullback Tim Riggins, who goes on to star most consistently on the field in the fictional football games of Friday Night Lights over the course of the first three seasons - and also do far more onscreen drinking than any other player portrayed. He begins the series squarely on point with the Billy Clyde Puckett model, living a self-centered life of almost constant womanizing and hard partying. His football talent in a football-obsessed town gives him a free ride at school and with one girl after another, while the fact that his father and mother are both out of the picture and he lives with an older brother gives him total freedom from parental restraints. Most of his time on screen involves drinking, often heavily.

Over the course of the 50 episodes of Friday Night Lights' first three seasons, Tim Riggins is shown drinking in 36. Although there are some occasions when his drink of 
choice varies, that choice is most often beer. During the first three seasons, the number of beers that Tim is either shown drinking on screen or suggested to have drunk off screen - based on indications such as the number of empty beer bottles around him during drinking scenes and the quantity of beer that he acquires before drinking scenes - is estimated by this research to be a minimum of 80 and quite possibly more than 220 . The minimum represents the number of beers that Tim is shown drinking on screen, while the second figure includes that number plus the total number he is suggested to have drunk off screen - based on the indications noted above. If his per-episode beer drinking is calculated based on that estimate for the entire first 50 episodes, that would place the figure at between 1.6 and 4.4 beers per episode. If that calculation is made based on the 36 episodes in which he drinks, it would place his per-episode beer consumption at between 2.22 and 6.11. Thus, given that the character Tim Riggins typically has around three minutes of time on screen per 45-minute episode, his overall beer consumption can conservatively be estimated to fall somewhere between one-half and two beers for every minute of screen time - or quite plausibly characterized as a beer a minute.

In tracking the social meanings embedded within all that drinking, this analysis finds construction of a set of themes that serve to hold together the broader framing of a nuanced relationship between masculinity and alcohol that can be constructive, destructive, or neutral, and which can advance an antiheroic or heroic model of behavior. The latter two themes are developed more strongly in the texts that are the subject of this analysis, but the presence of others must also be considered in order to accurately summarize the findings. In the analysis sections that follow, the broader framing will be deconstructed in terms of those five significant themes and will be discussed in terms of how they particularly shape the narrative mediation of the Tim Riggins character. Through the Billy Clyde Puckett model, he interacts with alcohol as a force that can be constructive, destructive, or neutral - but through which the character can also be pulled from the Billy Clyde/antihero model toward the Merriwell/heroic model in something of a reversal of the historical progression of mediated representations discussed further above.

\section{Representations of drinking as part of constructive outcomes}

In its development of story lines over the first three seasons of Friday Night Lights, the words, images, and thematic emphasis, in terms of Altheide's approach to document analysis, "carry the discourse that reflects certain themes, which in turn are held together and given meaning by a broad frame" (Altheide, 1996: 31). This section considers the discourse of Friday Night Lights that regularly utilizes such elements that represent alcohol use by Tim Riggins and other characters in the context of drinking as part of constructive outcomes. Often this theme is advanced through narrative developments involving the Dillon High School football coach, Eric Taylor. He often resolves various domestic issues with his wife - such as working out issues involved in having a second child unexpectedly - over a glass of wine (Who Do You Think You Are?, 2008), as well as working through problems involving other characters while sharing a drink. Coach Taylor, for example, shares a drink with an older assistant coach while working out problems the latter has with a star black player (Black Eyes and Broken Hearts, 2007). 
The theme of drinking as part of constructive outcomes is also advanced quite extensively through narrative developments involving Tim Riggins. He is drinking beer, for example, when he persuades a group of former players to take on the purchase of a house to renovate and sell (Every Rose Has Its Thorn, 2009). Indeed, in every scene in which Tim and the others are working on the remodeling or even discussing it, they are drinking beer (It Ain't Easy Being J.D. McCoy, 2009; Keeping Up Appearances, 2009). Yet despite all the drinking, the young men complete the rather extensive renovations ahead of schedule. They celebrate and plan the use of their profits with still more drinking ( $\mathrm{New}$ York, New York, 2009). Another example can be seen in the way Tim and other players are often portrayed as gathering on the school football field on various nights when it is closed to drink and bond in various ways. (On Friday Night Lights, the players always seem to have not only access to the game field at any hour but to the lighting and publicaddress systems as well.) For example, a group of current and former players gather on one such night with multiple six-packs of beer to celebrate having helped one of the former players rehabilitate an injured knee and win a college football scholarship (Hello, Goodbye, 2009).

\section{Representations of drinking as part of destructive outcomes}

Just as regularly, the discourse of Friday Night Lights utilizes words, images, and thematic emphasis that represent alcohol use by Tim Riggins and other characters in the context of drinking as part of destructive outcomes. This further contributes to the broader framing of a nuanced relationship between masculinity and alcohol that this analysis finds to be consistent over the course of the first three seasons of Friday Night Lights. In an interview before football practice, a television reporter smells alcohol on the breath of Tim Riggins and asks if he has been drinking. Tim denies it but his intoxication becomes obvious through his repeated mistakes once practice begins (Pilot, 2007). At the drive-in that is the main hangout for high school students, a drunken Tim gets into an argument and near fight with another player, who tells Tim to "go home and sleep it off" (Eyes Wide Open, 2007). In another episode, as Tim drinks his way through a sixpack and largely ignores her, a girlfriend breaks up with him, telling him he is "just another mediocre football player who is going to grow up to drink himself to death" (Wind Sprints, 2007).

Other characters also are regularly depicted in the context of drinking as part of destructive outcomes. A player who generally does not drink is talked into going with other players and drinking heavily in a hot tub with several of the team's cheerleaders and photos of the party posted online cost him the girlfriend he really cares about (Upping the Ante, 2007). A leading team booster's drinking contributes to his wife leaving him and to humiliating behavior by him in front of many townspeople at a postgame party (Bad Ideas, 2008). Even Coach Eric Taylor uncharacteristically drinks in excess in a moment of rivalry with an ex-boyfriend of his wife, and the two eventually wind up in a drunken wrestling match among the white-linened tables at an upscale restaurant (May the Best Man Win, 2008). 


\section{Representations of drinking as part of neutral outcomes}

Also among the discourse of Friday Night Lights that contributes to the broader framing of a nuanced relationship between masculinity and alcohol is the utilization of words, images, and thematic emphasis that represent alcohol use by Tim Riggins and other characters in the context of drinking as part of neutral outcomes. In this line of discourse, the drinking cannot be said to provide any substantial embedding of social meanings other than the presence of drinking as a minor narrative fixture that contributes to neither constructive nor destructive outcomes in those instances. In examples of such representations, drinking takes place on screen but has no material influence on any particular outcome. In some instances, Tim Riggins' beer drinking is seen only in passing (Mud Bowl, 2007), or in other typical cases, various characters are shown briefly drinking at parties, or in restaurants or bars (I Think We Should Have Sex, 2007; Who's Your Daddy, 2007).

\section{Representations of drinking as part of advancing the Billy Clyde/ antihero model}

The discourse of Friday Night Lights that most strongly reflects themes that contribute meaning in the context of the broader framing of drinking is that which this analysis finds can be expressed in terms of either advancing representations of Tim Riggins through the Billy Clyde/antihero model or through the Merriwell/heroic model. Most significantly, the discourse consistently works over time to place Riggins in a struggle between the two, with on balance the latter dominant in the social meanings embedded in his story.

At the beginning of the series, and to some extent throughout, Tim is framed strongly and vividly in terms of the Billy Clyde/antihero model. Early on, his ethos is summarized by a cheerleader who tells him: “Tim, I know you don't ever do anything you don't want to do, and I guess that's fine" (Wind Sprints, 2007). In the series-opening episode, he is first seen passed out on the living-room sofa in the home where he and his older brother live, a half-dozen empty beer bottles on the coffee table next to him. As his brother tries to rouse him for football practice, Tim is joined by a young woman wearing apparently nothing more than an unbuttoned dress shirt of Tim's. His frustrated brother walks off muttering, "This is life, not Maxim magazine" (Pilot, 2007). In the opening episode of Season Two, Tim, carrying a case of beer to his truck, runs into a churchgoing young woman who counsels him not to "go around bragging that you spent your entire summer in a drunken stupor." He grins and tells her he spent much of it "in a three-way with the Stratton sisters" (Last Days of Summer, 2008). In the opening episode of Season Three, as a sports talk-show host speaking in voiceover tells his radio audience that Tim Riggins must be in top condition to carry more of the team offense in the upcoming season, a series of shots shows him lolling in a swimming pool with girls, drinking a series of beers and then finally throwing up (I Knew You When, 2009).

Such framing is further advanced by having other players on the team discuss Tim's legendary exploits, such as the time he "was so drunk he fell asleep on the kickoff" (How the Other Half Lives, 2009). When the coach asks Tim to help a younger player whose 
family has recently moved to town feel more a part of the team, Tim first shows him where underage athletes can buy alcohol. "If you ever need to get away from anything, anyone, you will go in there. You hear me? Smitty's - best bar on the planet," Tim advises. When the younger athlete says he doesn't drink, Tim replies, uncomprehending, "What do you mean, you don't drink?" (It Ain't Easy Being J.D. McCoy, 2009).

It is in the representations of Tim drinking with his best friend, Jason Street, in the opening season of Friday Night Lights that the meaning-making sets up the subsequent framing efforts that will place Tim in a long running struggle between the Billy Clyde/ antihero model and the Merriwell/heroic model. The night before the first game of the series' first season, Tim sits by a campfire with Jason and other players, drinking one beer after another from an ice chest. He tells Jason - who at that point is a superstar quarterback on the rise - that once the latter starts making big money in professional football, Tim will always look out for the ranch Jason will buy back home. "Here's to God and football and good friends living large together. Texas forever," Tim proclaims, raising a beer (Pilot, 2007). Later, after an injury in that first game leaves Jason a paraplegic, Tim at first can't bring himself to visit his disabled friend for weeks, then utilizes beer to work through the situation. He spirits Jason out of a rehabilitation center and stocks up on beer; then they ride in his truck to a lake with Jason's girlfriend, where Tim promises, "The three of us, we'll rise up, get through anything" (El Accidente, 2007).

\section{Representations of drinking as part of advancing the Merriwell/heroic model}

Finally, this analysis finds the discourse of Friday Night Lights that most significantly works to embed social meanings in its broader framing of drinking is that in which the Tim Riggins character is pulled from the Billy Clyde/antihero model toward the Merriwell/heroic model. As the sections above demonstrate, Friday Night Lights does not utilize words, images, and thematic emphasis that represent alcohol use by Tim Riggins and other characters in a simplistic or monolithic manner, but rather a nuanced one in the context of multiple outcomes. Yet among those outcomes, the most dominant framing works toward, in effect, something of a reversal of the historical progression through which mediated representations of football players shifted from the Merriwell/ heroic model to the Billy Clyde/antihero model - pulling Tim increasingly over the first three seasons into modes more akin to the former.

That process is set in motion through representations in which Tim must face consequences of his "Billy Clyde" lifestyle, beginning with his betrayal of his best friend Jason by sleeping with his girlfriend Lila. Jason does not find out for a time, but Lila's guilt eventually leads her to end the affair, telling Tim "God, it's not even 7 o'clock and you can barely stand," while gesturing at the drink in his hand. "If you think getting drunk is going to make this any easier, you're wrong. It's not cool or charming. It's just pathetic and gross and I feel sorry for you. I really do." Wrestling through increasing confrontations with the ways that his hard drinking contradicts his belief in it as a successful way of life, midway through the first Friday Night Lights season Tim announces he is going to quit drinking. Friends are derisive and skeptical, but he actually does abstain for a time, during which he has his best football game to date (Homecoming, 
2007). But his fledgling efforts in the direction of the Merriwell model collapse when Jason realizes Tim has betrayed him and ends their friendship. Tim begins drinking again (Crossing the Line, 2007).

But from then on, the struggle over which model - Billy Clyde/antihero or Merriwell/ heroic - Tim will embrace continues throughout the first three seasons of Friday Night Lights. In narrative development, it plays out first as Tim wrestles with a growing realization that his absent father - something of an aging Billy Clyde Puckett - is not the larger-than-life figure he had long idealized but a petty thief who is dishonest even with his adoring son (Upping the Ante, 2007). Toward the end of Season One, a series of discoveries leads Tim to seek a form of redemption for helping his father hustle an unsuspecting victim in barroom pool by returning later to allow the sucker to gain vengeance by beating up Tim outside the bar (I Think We Should Have Sex, 2007). Later, Tim manages to win Jason's forgiveness by the end of the series' first season through an effort that involves finding a way to make the wheelchair-bound Jason a part of the football team again as well as several cases of beer consumed with other players in the course of hanging out overnight on the high school field (Ch-Ch-Ch-Ch-Changes, 2007).

The framing effort continues to pull Tim back from antiheroic to heroic through drinking efforts in which he has similarly higher purposes. Tim accompanies Jason on a trip to Mexico for risky surgery that is illegal in the United States but which Jason is convinced will enable him to walk again. By drinking heavily with Jason for weeks, persuading Lila to join them, and ultimately arranging an intervention on a "booze cruise," Tim ultimately convinces Jason not to undergo the surgery and to return to Texas (Are You Ready for Friday Night, 2008; Backfire, 2008; Let's Get It On, 2008). Later, Tim goes to similarly heroic lengths to help Jason launch a career at a sports agency in New York City, after which they part company with a fist bump and a final vow of "Texas forever" (New York, New York, 2009). Thus, it is the framing effort to pull Tim toward the "Merriwell" model that ultimately imbues that "Texas forever" promise with meaning far more authentic than when Tim uttered the same words while still squarely within the Billy Clyde model.

Over the course of the first three seasons, Tim goes on to push himself to additional heroic efforts that lead to better lives for various characters, including his brother and Lila, as well as lesser efforts for the sake of other characters. He must earn his way back onto the football team after missing practices and games while on a drunken road trip, as well as to free himself from a harrowing entanglement with a temporary roommate who turns out to be a violent methamphetamine dealer (Humble Pie, 2008; Seeing Other People, 2008). He is forced to endure extended and undeserved punishment from his coach who mistakenly jumps to the conclusion - based on Tim's "Billy Clyde" reputation - that the player was trying to take advantage of his daughter (The Confession, 2008; There Goes the Neighborhood, 2008). And near the end of Friday Night Lights' third season, Tim works determinedly to persuade Lila, who has begun drinking heavily and skipping school after her father blows her college fund on a foolish investment, to find a way to follow through on her plans to attend college (A Hard Rain's Gonna Fall, 2009). Thus, over the course of the first three seasons of the series, in a number of ways, the Tim Riggins character is successfully pulled from the Billy Clyde/antihero model toward the Merriwell/heroic model. 


\section{Conclusion}

This analysis suggests that the dominant frame developed consistently over the first three seasons of Friday Night Lights embeds nuanced social meanings in its framing of alcohol use by the series' dominant football player, and other characters, so as to associate it with multiple potential outcomes. Among those outcomes, the most dominant framing works to, in effect, reverse a progression deeply rooted in decades of football representations that historically evolved from a heroic model toward an antihero model, with heavy drinking central to that narrative process of meaning-making in such messages. The character of Tim Riggins begins the television series as one of the most recent mediated manifestations of the Billy Clyde/antihero model of self-centered womanizing and hard partying. But over the course of the series, the framing works to pull him toward the virtues of the Merriwell/heroic model. Within the telling of the story of a hard-drinking fullback from a small town in Texas, we see the construction of diverse masculinities in a manner that advances understanding of how such masculinities are shaped socially and historically and as subject positions in relation to media representations.

In its construction of story lines over the first three seasons of Friday Night Lights, the words, images, and thematic emphasis that are employed provide support for this cultural analysis's assertions in terms of Altheide's approach to document analysis, by carrying "the discourse that reflects certain themes, which in turn are held together and given meaning by a broad frame" (1996: 31). The dominant framing identified in this study's analysis also is useful in terms of Gamson's conceptualization of the media frame as "a central organizing idea used for making sense of relevant events," that can help explain how audiences may "understand and remember a problem" (1989: 157). When it comes to heavy drinking and masculinity as represented by Friday Night Lights, audiences are provided multiple potential outcomes to consider through the meaning-laden use of historical models.

\section{Funding}

This research received no specific grant from any funding agency in the public, commercial, or not-for-profit sectors.

\section{References}

A Hard Rain's Gonna Fall (2009) Friday Night Lights: The Third Season [DVD]. Universal City, CA: Universal Studios.

Altheide DL (1996) Qualitative Media Analysis. Thousand Oaks, CA: SAGE.

Are You Ready for Friday Night? (2008) Friday Night Lights: The Second Season [DVD]. Universal City, CA: Universal Studios.

Backfire (2008) Friday Night Lights: The Second Season [DVD]. Universal City, CA: Universal Studios.

Bad Ideas (2008) Friday Night Lights: The Second Season [DVD]. Universal City, CA: Universal Studios.

Bellafante G (2007) Randy teenagers, troubled parents, feverish thoughts and even football. The New York Times, 5 October, B17.

Beynon J (2002) Masculinities and Culture. Buckingham: Open University Press.

Bissinger HG (2004) Return to Odessa. Sports Illustrated, 4 October, 50-55. 
Black Eyes and Broken Hearts (2007) Friday Night Lights: The First Season [DVD]. Universal City, CA: Universal Studios.

Brailsford D (1969) Sport and Society: Elizabeth to Anne. London: Routledge \& Kegan Paul.

Breed W and DeFoe J (1979) Themes in magazine alcohol advertisements: A critique. Journal of Drug Issues 9: 511-522.

Cafiso J, Goodstadt MS, Garlington WK, et al. (1982) Television portrayal of alcohol and other beverages. Journal of Studies on Alcohol 43: 1232-1243.

Camp W (1984) Walter Camp's book of college sports. In: Riess SA (ed) The American Sporting Experience: A Historical Anthology of Sport in America. New York: Leisure, pp. 165-167.

Carey JW (1974) The problem of journalism history. Journalism History 1(1): 3-5, 27.

Ch-Ch-Ch-Ch-Changes (2007) Friday Night Lights: The First Season [DVD]. Universal City, CA: Universal Studios.

Clark JB (1993) 3rd Down and Forever: Joe Don Looney and the Rise and Fall of an American Hero. New York: St. Martin's Press.

Cohen M (1996) Fashioning Masculinity: National Identity and Language in the Eighteenth Century. London: Routledge.

Connell B (1995) Masculinities. Cambridge: Polity Press.

Crossing the Line (2007) Friday Night Lights: The First Season [DVD]. Universal City, CA: Universal Studios.

Crowther NB (1996) Sports violence in the Roman and Byzantine Empires: A modern legacy? International Journal of the History of Sport 13(3): 445-487.

Dawson G (1994) Soldier Heroes: British Adventure, Empire and the Imagining of Masculinities. London: Routledge.

Dunnavant K (2004) The Fifty-Year Seduction: How Television Manipulated College Football, from the Birth of the Modern NCAA to the Creation of the BCS. New York: St. Martin's Press.

DuRant RH, Rome ES, Rich M, et al. (1997) Tobacco and alcohol use behaviors portrayed in music videos: A content analysis. American Journal of Public Health 87(7): 1131-1135.

El Accidente (2007) Friday Night Lights: The First Season [DVD]. Universal City, CA: Universal Studios.

Entman RM (1991) Framing U.S. coverage of international news. Journal of Communication 41(4): 6-27.

Entman RM (1993) Framing: Toward clarification of a fractured paradigm. Journal of Communication 43(4): 51-58.

Every Rose Has Its Thorn (2009) Friday Night Lights: The Third Season [DVD]. Universal City, CA: Universal Studios.

Eyes Wide Open (2007) Friday Night Lights: The First Season [DVD]. Universal City, CA: Universal Studios.

Falk G (2005) Football and American Identity. New York: Haworth.

Gamson WA (1989) News as framing. American Behavioral Scientist 33(2): 157-161.

Gamson WA and Modigliani A (1989) Media discourse and public opinion on nuclear power: A constructionist approach. American Journal of Sociology 95(1): 1-37.

Garner T (2008) They'll leave the lights on for you. The Sporting News, 17 March, 8.

Gems GR (2000) For Pride, Profit, and Patriarchy: Football and the Incorporation of American Cultural Values. Lanham, MD: Scarecrow Press.

Gerbener G, Gross L and Morgan M (1986) Living with television: The dynamics of the cultivation process. In: Bryant J and Zillman D (eds) Perspectives on Media Effects. NJ: Lawrence Erlbaum. 
Gerbener G, Gross L, Morgan M, et al. (1981) Health and medicine on television. New England Journal of Medicine 15(305): 901-904.

Gitlin T (1980) The Whole World is Watching: Mass Media in the Making and Unmaking of the Left. Berkeley, CA: University of California.

Grossman B (2007) NBCU effort aims to keep "Lights" on. Broadcasting \& Cable, 23 July, 3.

Heffernan V (2006) On the field and off, losing isn't an option. The New York Times, 3 October, E1.

Hello, Goodbye (2009) Friday Night Lights: The Third Season [DVD]. Universal City, CA: Universal Studios.

Hobsbawm E (1983) Introduction: Inventing tradition. In: Hobsbawm E and Ranger T (eds) The Invention of Tradition. Cambridge: Cambridge University Press, pp. 1-14.

Homecoming (2007) Friday Night Lights: The First Season [DVD]. Universal City, CA: Universal Studios.

How the Other Half Lives (2009) Friday Night Lights: The Third Season [DVD]. Universal City, CA: Universal Studios.

Humble Pie (2008) Friday Night Lights: The Second Season [DVD]. Universal City, CA: Universal Studios.

I Knew You When (2009) Friday Night Lights: The Third Season [DVD]. Universal City, CA: Universal Studios.

It Ain't Easy Being J.D. McCoy (2009) Friday Night Lights: The Third Season [DVD]. Universal City, CA: Universal Studios.

I Think We Should Have Sex (2007) Friday Night Lights: The First Season [DVD]. Universal City, CA: Universal Studios.

Keeping Up Appearances (2009) Friday Night Lights: The Third Season [DVD]. Universal City, CA: Universal Studios.

Kennedy E (2007) Watching the game: The theorizing masculinities in the context of mediated tennis. In: Aitchison CC (ed) Sport \& Gender Identities: Masculinities, Feminities, and Sexualities. New York: Routledge, pp. 22-33.

Last Days of Summer (2008) Friday Night Lights: The Second Season [DVD]. Universal City, CA: Universal Studios.

Let's Get It On (2008) Friday Night Lights: The Second Season [DVD]. Universal City, CA: Universal Studios.

McEntegart PL, Wertheim J, Menez G, et al. (2002) The top 100 sports books of all time. Sports Illustrated, 16 December, 128.

Malone M (2006) Berg brings his “A” game. Broadcasting \& Cable, 24 July, 22.

Mangan JA (1981) Athleticism in the Victorian and Edwardian Public School. London: Cambridge University Press.

Mathios A, Avery R, Shanahan J, et al. (1998) Alcohol portrayals on prime-time television: Latent and manifest messages. Journal of Studies on Alcohol 59(3): 305-310.

May the Best Man Win (2008) Friday Night Lights: The Second Season [DVD]. Universal City, CA: Universal Studios.

Moore JH (1984) Football's ugly decades, 1893-1913. In: Riess S (ed) The American Sporting Experience: A Historical Anthology of Sport in America. New York: Leisure, pp. 168-189.

Mud Bowl (2007) Friday Night Lights: The First Season [DVD]. Universal City, CA: Universal Studios.

New York, New York (2009) Friday Night Lights: The Third Season [DVD]. Universal City, CA: Universal Studios.

Oriard M (1982) Dreaming of Heroes: American Sports Fiction, 1868-1980. Chicago, IL: NelsonHall.

Oriard M (1991) Sporting with the Gods: The Rhetoric of Play and Game in American Culture. New York: Cambridge University Press. 
Oriard M (1993) Reading Football: How the Popular Press Created an American Spectacle. Chapel Hill, NC: University of North Carolina Press.

Oriard M (2001) King Football: Sport and Spectacle in the Golden Age of Radio and Newsreels, Movies and Magazines, the Weekly and the Daily Press. Chapel Hill, NC: University of North Carolina.

Oriard M (2007) Brand NFL: Making and Selling America's Favorite Sport. Chapel Hill, NC: University of North Carolina.

Pilot (2007) Friday Night Lights: The First Season [DVD]. Universal City, CA: Universal Studios.

Polumbaum J and Wieting SG (1999) Stories of sport and the moral order: Unraveling the cultural construction of Tiger Woods. Journalism and Communication Monographs 1(2): 69-118.

Poniewozik J (2011) Friday Night Lights, “Always.” Available at: http://www.time.com/time/ specials/packages/article/0,28804,2101344_2101174,00.html (accessed 25 May 2013).

Roper M and Tosh J (eds) (1991) Manful Assertions: Masculinity in Britain Since 1800. London: Routledge.

Sage GH (1998) Power and Ideology in American Sport. Champaign, IL: Human Kinetics.

Seeing Other People (2008) Friday Night Lights: The Second Season [DVD]. Universal City, CA: Universal Studios.

Sides H (2007) The outside 100. Outside, December, 97.

Smith RA (1981) Harvard and Columbia and a reconsideration of the 1905-06 football crisis. Journal of Sport History 8(3): 5-19.

The Confession (2008) Friday Night Lights: The Second Season [DVD]. Universal City, CA: Universal Studios.

There Goes the Neighborhood (2008) Friday Night Lights: The Second Season [DVD]. Universal City, CA: Universal Studios.

Upping the Ante (2007) Friday Night Lights: The First Season [DVD]. Universal City, CA: Universal Studios.

Van Zoonen L (1991) Feminist perspectives on the media. In: Curran J, Morley D and Walkerdine V (eds) Cultural Studies and Communications. London: Edward Arnold, pp. 33-54.

Wallack L (1980) Mass media and alcohol, smoking and drug taking. Contemporary Drug Problems (Spring): 49-83.

Wallack L, Grube JW, Madden PA, et al. (1990) Portrayals of alcohol on prime-time television. Journal of Studies on Alcohol 51(5): 428-437.

Wenner LA and Jackson SJ (2009) Sport, beer, and gender in promotional culture: On the dynamics of a holy trinity. In: Wenner LA and Jackson SJ (eds) Sport, Beer, and Gender: Promotional Culture and Contemporary Social Life. New York: Peter Lang, pp. 1-32.

Whannel G (2007) Mediating masculinities: The production of media representations in sport. In: Aitchison CA (ed) Sport \& Gender Identities: Masculinities, Feminities, and Sexualities. New York: Routledge, pp. 7-21.

Who Do You Think You Are? (2008) Friday Night Lights: The Second Season [DVD]. Universal City, CA: Universal Studios.

Who's Your Daddy (2007) Friday Night Lights: The First Season [DVD]. Universal City, CA: Universal Studios.

Wiedemann T (1992) Emperors and Gladiators. London: Routledge.

Wilkinson B (1955) Oklahoma 20, Missouri 0. Bud Wilkinson's Football Letter, 8 November, 2 (Athletic Department Collection, University Archives. Western History Collections, University of Oklahoma).

Wind Sprints (2007) Friday Night Lights: The First Season [DVD]. Universal City, CA: Universal Studios. 